\title{
Regimen of Indomethacin Therapy in Acute Gouty Arthritis
}

\author{
B. T. EMMERSON,* M.D., M.R.A.C.P.
}

Brit. med.F., 1967, 2, 272-274

Though colchicine has been famed for centuries for its effect in acute gouty arthritis its relief of pain and inflammation in this condition is not invariable and may not be apparent for 24 hours or more. It was therefore not surprising that when phenylbutazone was introduced colchicine was largely replaced by this preparation, which was more certain in its action. Highdosage phenylbutazone therapy, however, was occasionally associated with marrow depression (Mauer, 1955). In 1963 indomethacin was reported to be an effective anti-inflammatory agent in a number of rheumatic diseases (Katz et al., 1963 ; Norcross, 1963 ; Rothermich, 1963). In acute gouty arthritis Hart and Boardman (1963) reported favourable results with the use of $300 \mathrm{mg}$. of indomethacin given in divided doses during the first 24 hours, with a gradual subsequent reduction to $100-150 \mathrm{mg}$. daily. The dose was varied from day to day according to the response, and treatment was continued for at least five days, or longer if symptoms persisted. Smyth et al. (1963) also obtained good results with indomethacin in acute gouty arthritis, using doses of $600-900 \mathrm{mg}$. on the first day and $400 \mathrm{mg}$. daily in divided doses during the next three to five days.

It therefore seemed that indomethacin was useful in acute gouty arthritis, but that dosage schedules varied widely and needed frequent review. Thus there seemed a need for a standardized regimen of treatment which would be uniformly successful but simple enough to leave in the hands either of patients or of nursing staff without constant supervision, and which would vary inherently with the severity of the gout and the response. Such a schedule might well be comparable to the usual schedule of oral colchicine treatment, in which the dosage varied with the response and toxic effects. The above considerations therefore led to the choice of the following therapeutic regimen: $100 \mathrm{mg}$. of indomethacin four-hourly until most pain was relieved, then $100 \mathrm{mg}$. eight-hourly for 24 hours, then $75 \mathrm{mg}$. eight-hourly for 24 hours, and then $50 \mathrm{mg}$. eighthourly for 24 hours.

This regimen was tested for effectiveness in patients with acute gouty arthritis. At the same time undesirable side-effects were sought and opportunities were taken to determine whether improvement in the regimen, such as a reduction in dosage, was possible.

\section{Patients}

Twenty-two patients (see accompanying Table) were treated with the above regimen over a period of two years. Initially, patients were observed in hospital, where regular assessment of response was made. Later a few were treated as outpatients and came to the hospital daily for assessment. The severity of the arthritis in this group varied greatly, but a large proportion had severe gout and had been referred because of difficulty in control of hyperuricaemia. In half of the patients more than one joint was acutely inflamed.

\section{Results}

There was a rapid and striking response to this regimen of treatment with indomethacin, details of which are shown in the Table. The severe pain had usually begun to ease within a couple of hours, and relief of pain at rest was in most cases complete within 24 hours. Some patients with podagra were able to wear a shoe next day. A typical response (Case 1) is shown in the Chart, where it is seen that as the regimen produced subsidence of inflammation a steady increase in the range of movement in the knee and a reduction in the circumference of the joint occurred. In the Table the column entitled "Preference to Other Therapy" refers to the patient's preference for indomethacin over other forms of treatment, such as colchicine or phenylbutazone, which had been administered for previous acute attacks. Those who developed second attacks of acute gouty arthritis were asked if they would agree to undergo treatment with either colchicine or phenylbutazone on the second occasion in order that the response could be compared with that to indomethacin. All declined, however, preferring to have indomethacin again, chiefly because of the rapidity of relief from pain.

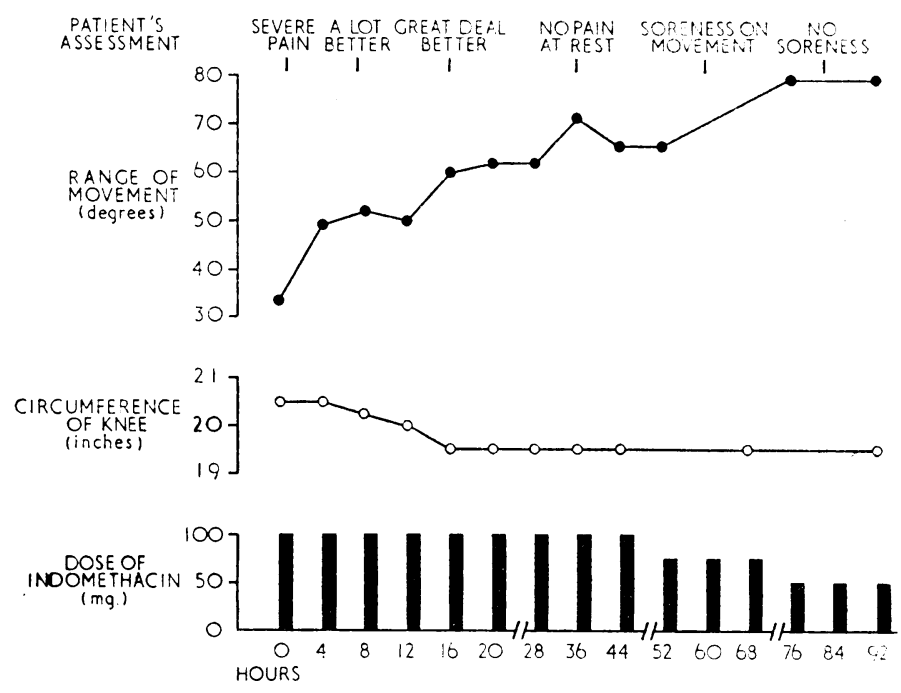

Response to the indomethacin regimen in Case 1, showing the dose given at the various time intervals (in hours), with the corresponding circumference of the affected joint, the increasing range of movement, and the patient's subjective assessment of the pain at the different times.

Opportunities also presented themselves for determining whether the dose of indomethacin could be reduced and yet an effective response be maintained. One patient (Case 13) taking $350 \mathrm{mg}$. of indomethacin in 30 hours for a mild attack of gout did not lose his pain at rest for 60 hours, and even then his arthritis responded only incompletely. Three patients (Cases 19,20 , and 21) either were given a small initial course of 300 to $500 \mathrm{mg}$. or the course had to be interrupted because of an intercurrent development. After the initial improvement in these patients relapse occurred within 24 hours, making necessary a further course of treatment, which was sometimes more than would have been expected had the interruption not occurred. On the other hand, the patient who did not respond to the indomethacin regimen (Case 11) did not respond to a subsequent course of colchicine or phenylbutazone. In retrospect it is thought that a response may have been obtained had the dosage

* Reader in Medicine, Medical Professorial Unit, Princess Alexandra Hospital, Brisbane, Queensland, Australia. 
of indomethacin been increased further. Five patients still had slight residual pain or signs of inflammation when the course of indomethacin was completed ; because of this doses of $75 \mathrm{mg}$. of indomethacin a day were continued for a further one and four weeks. For these reasons it is not thought possible to lower the routine dose or to shorten the duration of indomethacin therapy to less than four days without the risk of recurrence of the gout. Even then one should be prepared to lengthen the regimen if complete subsidence has not occurred at that time, or to restart it if there is any early recurrence.

\section{Side-effects}

Patients were asked whether the indomethacin tablets had upset them in any way, and were later specifically questioned about symptoms of headache, giddiness, faintness, nausea, vomiting, dyspepsia, and diarrhoea. Out of the 22 patients only four developed headache during the treatment; one of these thought that the relief of the gout was fair compensation for the headache, and two commented that they "often got headaches, anyway." One patient admitted to slight giddiness during treatment ; two complained of "indigestion" and one of nausea when the indomethacin was taken on an empty stomach, with relief when taken after food. No patient was known to have a peptic ulcer. One patient noticed impairment of his capacity for mental concentration. Another (Case 20) developed vomiting and giddiness after $500 \mathrm{mg}$. of indomethacin, which was thereupon stopped. When his gout recurred 16 hours later he took a course of $1,325 \mathrm{mg}$. without further symptoms.

Because of the reported association with peptic ulceration (Norcross, 1963 ; Lövgren and Allander, 1964), the indo- methacin capsules were given whenever possible with food, but antacids were used only if epigastric discomfort occurred. Tests for faecal occult blood (chiefly using Haematest tablets) were carried out on any faeces passed. As no dietary restriction before starting treatment was possible, interpretation of the results was difficult. Comparison of the results with those reported by Goldman et al. (1964) in patients on a normal diet, however, failed to show any difference in the incidence of positive reactions at the different reading times. Thus no evidence was obtained that the preparation and dosage used in this trial induced any significant degree of occult alimentarytract bleeding. No anaemia developed.

\section{Discussion}

Apart from the mention of gout among reports of the use of indomethacin in other joint diseases (Barceló and Sans-Solá, 1965 ; Robinson, 1965 : Nelson, 1966), the only other specific study of the use of indomethacin in gout is that of Boardman and Hart (1965), who treated 26 patients. They also commented on the rapidity of relief, as $61 \%$ of their patients treated with indomethacin obtained relief within 48 hours as opposed to $12 \%$ of those treated with phenylbutazone. Their dosage range, however, varied widely, from 50 to $400 \mathrm{mg}$. daily initially when using tablets and from 75 to $150 \mathrm{mg}$. daily latterly when using the capsules. Their final recommendation was for dosages ranging from 25 to $50 \mathrm{mg}$. six-hourly, the exact level being determined by personal experience in the individual case. This is much lower than the schedule under study, and, as described in the results, total daily doses similar to theirs were ineffective in a number of our patients. It is quite apparent, however, that the present dose schedule produced even greater

Response of Patients with Acute Gout to Indomethacin Regimen

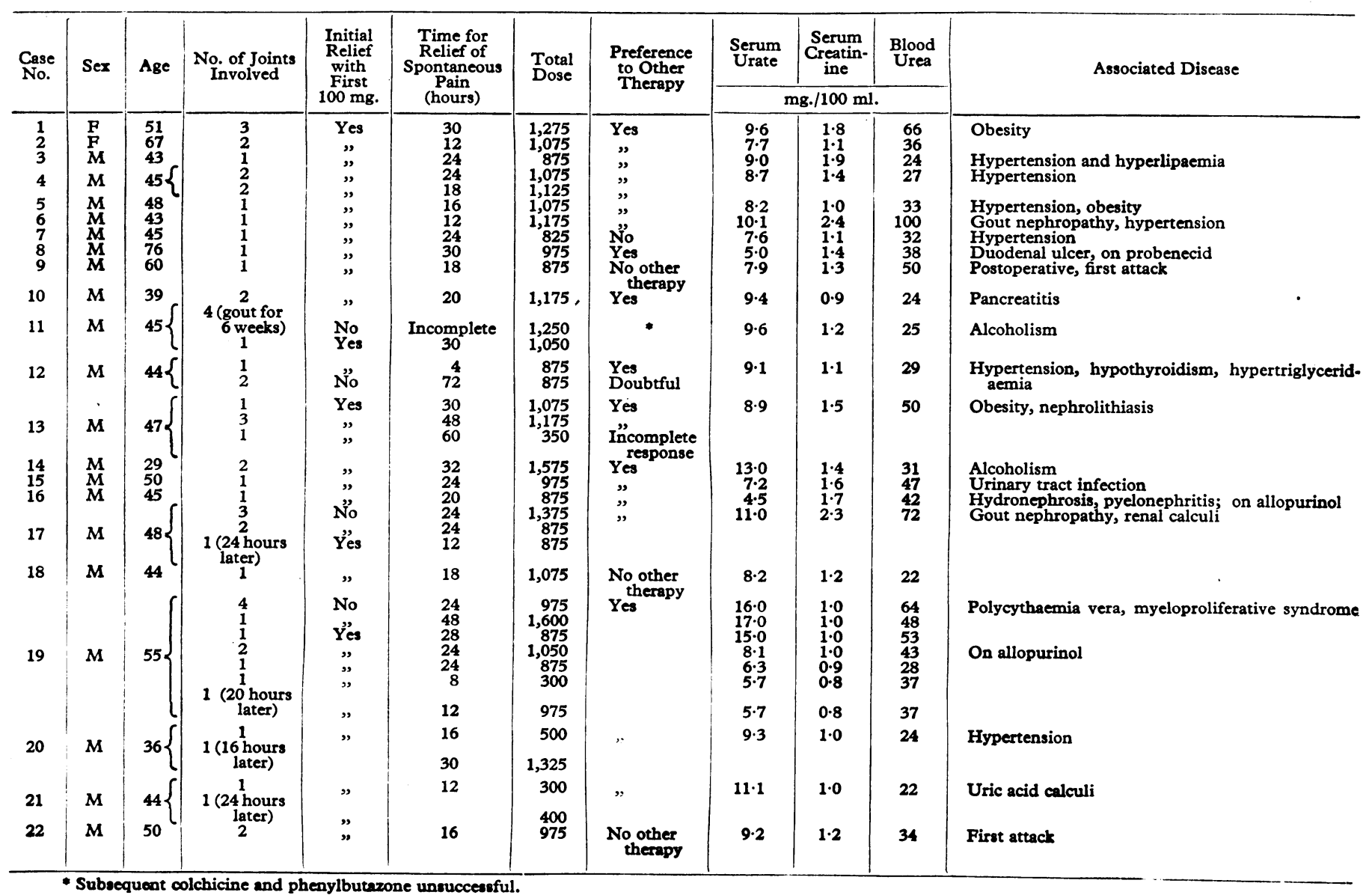


and more rapid relief of pain than the lower dose range, as 18 out of 22 patients obtained relief within the first four hours, a matter of importance in such a painful condition. The decisive factor would seem to be the severity of the gouty arthritis.

Boardman and Hart (1965) reported no response to indomethacin in four females with gout, but the two females in the group under study responded in a manner quite indistinguishable from that of the males-again the difference in response may be one of dosage. It would seem that the higher the dosage used the more rapid the response and the greater the proportion of patients responding. The factors limiting dosage then become the cost and the incidence of side-effects.

Reports of the use of indomethacin in other joint diseases (Hart and Boardman, 1965 ; Smyth, 1965) have included a high incidence of headache, giddiness, nausea, or vomiting. The incidence seemed to depend largely upon the daily dose of indomethacin administered, ranging from 30 to $80 \%$ with daily doses of 100 to $200 \mathrm{mg}$. This trial has therefore been unusual for the low incidence of side-effects found. Boardman and Hart (1965), using doses which sometimes reached $600 \mathrm{mg}$. daily, found a $30 \%$ incidence of side-effects in their gouty patients ; they also commented that these were not severe. Their lower dosage was therefore not associated with any reduction in the incidence of side-effects, though they thought that sideeffects were less severe in younger patients. It seems possible that patients with acute gout, who are relatively young and otherwise healthy, may be more tolerant of the side-effects of indomethacin than patients suffering from a chronic debilitating disease such as rheumatoid arthritis.

\section{Summary}

The results of treatment with a regimen of indomethacin therapy in 22 patients with acute gouty arthritis are described. The regimen consisted in administering $100 \mathrm{mg}$. of indomethacin by mouth four-hourly until most of the pain was relieved, after which administration was continued at eighthourly intervals with three doses of $100 \mathrm{mg}$., three of $75 \mathrm{mg}$., and three of $50 \mathrm{mg}$. This method has been shown to be very effective in producing rapid relief of pain and subsidence of the acute gouty arthritis and to be associated with a low incidence of side-effects.

I wish to acknowledge the assistance of the nursing staff of the university wards at the Princess Alexandra Hospital and their care in attending to details of administration and recording the response to treatment. I am grateful to Merck, Sharp, and Dohme (Australia) Pty. Ltd. for generous supplies of indomethacin (Indocid).

\section{REFERENCES}

Barceló, P., and Sans-Solá, L. (1965). A.I.R. Arch. interamer. Rhoum (Rio de F.), 8, 162.

Boardman, P. L., and Hart, F. D. (1965). Practitioner, 194, 560

Goldman, P., Paver, W. K. A. and Corbett, W. H. (1964). Med. I. Aust., 1, 755 .

Hart, F. D., and Boardman, P. L. (1963). Brit. med. 7., 2, 965.

Tat (1965). Ibid., 2, 1281.

Katz, A. M., Pearson, C. M., and Kennedy, J. J. (1963). Arthr. and Rheum., 6, 281.

Lövgren, O., and Allander, E. (1964). Brit. med. F., 1, 118.

Mauer, E. F. (1955). New Engl. 7. Med., 253, 404.

Nelson, S. (1966). Med. 7. Aust., 1, 988.

Norcross, B M. (1963). Arthr, and Rheum. 6, 290

Robinson, R. G. (1965). Med 7. Aust, 1, 266.

Rothermich, N. O. (1963). Arthr. and Rheum., 6, 295.

Smyth, C. J. (1965). Ibid., 8, 921 .

Smyth, Valayos, E. E., and Amoroso, C. (1963). Ibid., 6, 299.

\title{
Vasodilator Properties of Alcohol
}

\author{
J. A. GILLESPIE,* M.D., CH.M., F.R.C.S.
}

The facial flushing associated with the consumption of alcohol is a well-recognized phenomenon, and alcohol, often in the form of whisky, has been widely recommended as a useful peripheral vasodilator agent. There have been very few quantitative measurements reported of its effects on peripheral blood-flow in normal subjects, however (Abramson et al., 1941), and none in subjects with ischaemic legs, though intra-arterial alcohol therapy has been described (Edwards et al., 1952 ; Conrad and Green, 1964). The present paper gives the results of measurements undertaken to establish quantitatively the nature of the vasodilatation produced by alcohol, with particular reference to the effect of whisky on blood-flow in the legs both of healthy subjects and of those with occlusive peripheral arterial disease. The results have been compared with those obtained with the more commonly used vasodilator drugs, and the possible practical usefulness of whisky as a vasodilator is assessed. Brief mention is made of some pharmacological aspects of the vasodilator action of alcohol.

\section{Methods}

Blood-flow in the feet, calves, forearms, and wrists of healthy adult subjects, and of patients with occlusive arterial disease affecting the legs, was measured by venous occlusion plethysmography by means of mercury in rubber-strain gauges (Whitney,

- Senior Lecturer and Honorary Consultant Surgeon, St. George's Hospital, London.
1949). Plethysmograms from the wrist and foot are a record mainly of skin blood-flow, while those from the forearm and calf indicate largely muscle blood-flow. Blood-flow in the upper limb was also measured in patients after cervicodorsal sympathectomy for Raymond's phenomenon and hyperhidrosis. In all subjects alcohol was given either orally, in the form of Scotch whisky in a dose varying from 1 to $3 \mathrm{ml} . / \mathrm{kg}$. of body weight, or as a brachial-artery infusion of ethyl alcohol from a motordriven syringe.

In each experiment the subject, after a light meal, lay for approximately half an hour in the laboratory until his peripheral blood-flow was at a steady level. Thereafter the control resting blood-flows in the areas being investigated were recorded four times a minute for five minutes. When whisky was to be given orally it was taken, usually undiluted, during the next four minutes, and further blood-flows were measured for three- or four-minute periods at intervals of 15 minutes or less for the duration of the experiment. Venous blood was withdrawn for estimation of its alcohol content 30 and 60 minutes after consumption of the whisky, and at the end of the experiment the subject's urine was also collected for alcohol estimation. The alcohol content was measured by a modified Cavett method in the forensic laboratory of St. George's Hospital. In setting out the results of these experiments the blood-flow at any period has been expressed as the mean of all inflows recorded for that period, and, unless otherwise stated, all measurements in subjects given whisky orally relate to a dose of $2 \mathrm{ml} . / \mathrm{kg}$. of body weight. 